\title{
Over-expression of extracellular superoxide dismutase in mouse synovial tissue attenuates the inflammatory arthritis
}

\author{
Dong Hoon $\mathrm{Yu}^{1 *}$, Jun Koo $\mathrm{Yi}^{1 *}$, Hyung Soo Yuh ${ }^{1}$, \\ Seo jin Park', Hei Jung Kim ${ }^{1}$, Ki Beom Bae', \\ Young Rae Ji', Na Ri Kim', Si Jun Park', \\ Do Hyung Kim ${ }^{3}$, Sung Hyun Kim', \\ Myoung Ok Kim${ }^{4}$, Jeong Woong Lee ${ }^{5,6}$ and \\ Zae Young Ryoo ${ }^{1,6}$ \\ ${ }^{1}$ School of Life Sciences and Biotechnology \\ Kyungpook National University \\ Daegu 702-701, Korea \\ ${ }^{2}$ Hormel Institute \\ University of Minnesota \\ Minnesota 55912, USA \\ ${ }^{3}$ Department of Physics \\ Kyungpook National University \\ Daegu 702-701, Korea \\ ${ }^{4}$ Department of BT \\ Kyungpook National University \\ Sangju 742-711, Korea \\ ${ }^{5}$ Regenerative Medicine Research Center \\ Korea Research Institute of Bioscience and Biotechnology \\ Daejeon 305-806, Korea \\ ${ }^{6}$ Corresponding authors: Tel, 82-53-950-7361; \\ Fax, 82-53-943-6925; E-mail, jaewoong64@ hanmail.net (Z.Y.R.) \\ Tel, 82-42-860-4428; E-mail, jwlee@ kribb.re.kr (J.W.L.) \\ *These authors contributed equally to this work. \\ http://dx.doi.org/10.3858/emm.2012.44.9.060
}

Accepted 4 June 2012

Available Online 21 June 2012

Abbreviations: CIA, collagen induced arthritis; EC-SOD, extracellular superoxide dismutase; FLS, fibroblast-like synoviocyte; MEF, mouse embryonic fibroblast; RA, rheumatoid arthritis; ROS, reactive oxygen species

\begin{abstract}
Oxidative stress such as reactive oxygen species (ROS) within the inflamed joint have been indicated as being involved as inflammatory mediators in the induction of arthritis. Correlations between extracellular-superoxide dismutase (EC-SOD) and inflammatory arthritis have been shown in several animal mod-
\end{abstract}

els of RA. However, there is a question whether the over-expression of EC-SOD on arthritic joint also could suppress the progression of disease or not. In the present study, the effect on the synovial tissue of experimental arthritis was investigated using EC-SOD over-expressing transgenic mice. The over-expression of EC- SOD in joint tissue was confirmed by RT-PCR and immunohistochemistry. The degree of the inflammation in EC-SOD transgenic mice was suppressed in the collagen-induced arthritis model. In a cytokine assay, the production of pro-inflammatory cytokines such as, IL-1 $\beta$, TNF $\alpha$, and matrix metalloproteinases (MMPs) was decreased in fibroblast-like synoviocyte (FLS) but not in peripheral blood. Histological examination also showed repressed cartilage destruction and bone in EC-SOD transgenic mice. In conclusion, these data suggest that the over-expression of EC-SOD in FLS contributes to the activation of FLS and protection from joint destruction by depressing the production of the pro-inflammatory cytokines and MMPs. These results provide EC-SOD transgenic mice with a useful animal model for inflammatory arthritis research.

Keywords: arthritis, experimental; reactive oxygen species; rheumatoid arthritis; superoxide dismutase; synovial membrane

\section{Introduction}

Rheumatoid arthritis (RA) is an autoimmune disease involving hyper-proliferation of the synovial membrane and accumulation of activated $T$ cells and macrophages, leading to progressive joint destruction. The initiating event of RA is followed by the induction of an immune response that results in inflammation in the synovial membrane and the lining of the joint, that is usually composed of macrophage and fibroblast-like cells known as synoviocytes (Sweeney and Firestein, 2004). These cells can produce pro-inflammatory cytokines including tumor necrosis factor $\alpha$ (TNF $\alpha$ ), interleukin-1 $\beta$ (IL-1 $\beta$ ), interleukin-6 (IL-6) and interleukin-8 (IL-8), which can enhance synovial inflam- 
mation (Feldmann, 1994).

Oxidative stress such as reactive oxygen species (ROS) within the inflamed joint have been indicated as being involved as inflammatory mediators in the induction of arthritis (Goldring, 2004). These ROS include radicals such as superoxide $\left(\mathrm{O}_{2}{ }^{-}\right)$, hydroxyl radicals $\left(\mathrm{OH}^{-}\right)$and non-radical species, such as hydrogen peroxide $\left(\mathrm{H}_{2} \mathrm{O}_{2}\right)$. The ROS derived from activated macrophage and granulocytes infiltrating arthritic joints are involved in the pathogenesis of RA. A high level of ROS can lead to direct damage to hyaluronic acid (McCord, 1974), lipids (Tiku et al., 2000), cartilage matrix and DNA (Burkhardt et al., 1986). The ROS contribute to disease through the induction of pro-inflammatory cytokines. After a period of hypoxia, re-oxygenated human monocytes produce large amounts of IL-1 $\beta$ stimulated by ROS (Koga et al., 1992) and TNF $\alpha$ is produced by alveolar macrophages (Simeonova and Luster, 1995) and monocytes (Volk et al., 1999) after stimulation with ROS. ROS are responsible for collagen hydrolysis and activation of metalloproteinase, leading to the degradation of the extracellular matrix.

The superoxide dismutase (SOD) are antioxidant enzymes that catalyze the dismutation of superoxide into hydrogen peroxide and oxygen (Fattman et al., 2000). There are three different isoforms of SOD which exist in mammals, including cytoplasmic and nuclear CuZn-SOD (Tsan, 1997), mitochondrial Mn-SOD (Carlsson et al., 1995) and extracellular SOD (EC-SOD). Unlike $\mathrm{Cu} / \mathrm{Zn}-$ and Mn-SODs, EC-SOD is found in the extracellular matrix of tissue and extracellular fluids, such as serum, cerebrospinal, ascites, and synovial fluids (Ookawara et al., 1998; Marklund, 2002). Correlations between EC-SOD and inflammatory arthritis have been shown in several animal models of RA. The decreased levels of IL-1 $\beta$ and TNF $\alpha$ in the sera were observed in the collagen-induced arthritis (CIA) by a gene transfer of EC-SOD (lyama et al., 2001), and EC-SOD deficient mice showed marked increases in mRNA levels of these cytokines in the joints (Ross et al., 2004).

In the previous study, it has already been shown that the transfer of EC-SOD transgenic mouse embryonic fibroblast (MEF) represses the inflammatory arthritis (Yu et al., 2008). However, there is a question whether the over expression of EC-SOD on arthritic joint could also suppress the progression of disease or not. In the present study, the effect on the synovial tissue of experimental arthritis was investigated using EC-SOD over-expression model.

\section{Results}

\section{Over-expression of EC-SOD in the synovial tissue}

First of all, the over-expression of EC-SOD was investigated in joint tissues from transgenic mice. RT-PCR of the joint tissues of each mouse were performed. As shown in Figure 1, EC-SOD was highly over-expressed in transgenic mice compared with wild type littermates. Furthermore, immunohistochemistry was also performed to confirm the distribution and localization of EC-SOD in joint tissues using an antibody to EC-SOD. The positive staining was mainly seen in the lining layer of the synovium and endotherial cells in the sublining.

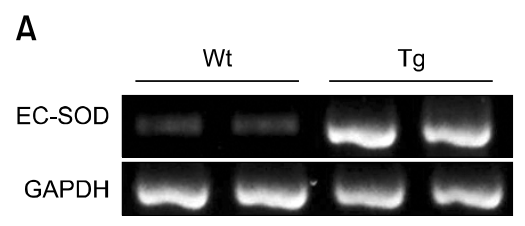

B

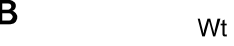

Wt $\mathrm{Tg}$

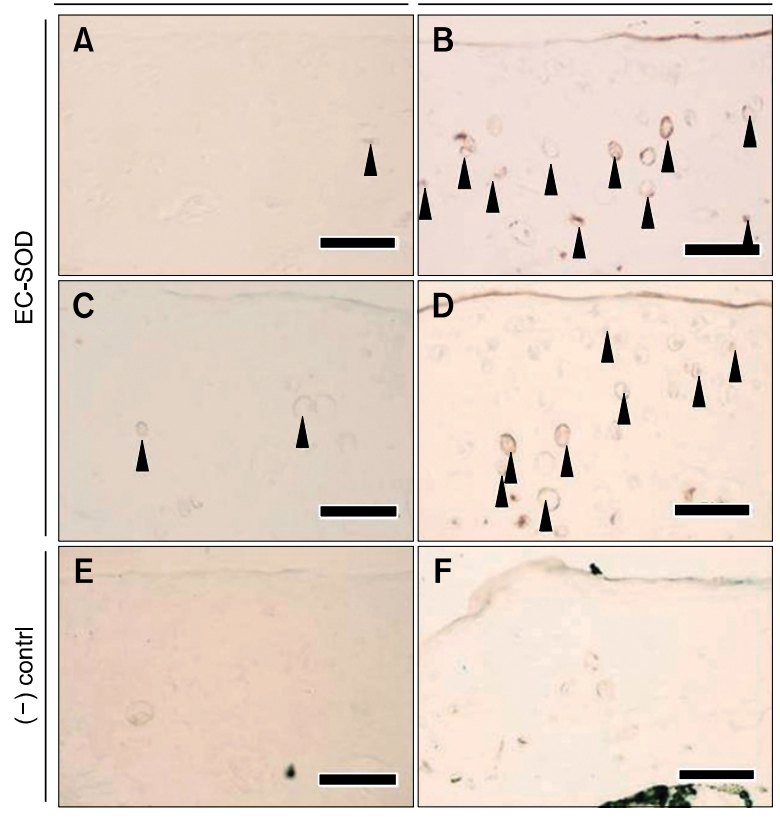

Figure 1. The EC-SOD over-expressed in joint tissue in transgenic mice. The over-expression of EC-SOD in transgenic mice was confirmed by RT-PCR (A). Total RNA was extracted from joint tissue of the transgenic and wild-type mice. GAPDH was used as control. Wt, wild type mice; Tg, EC-SOD transgenic mice. Further analysis of the location of over-expressed EC-SOD in transgenic mice was performed by immunohistochemistry $(B)$. The synoviums were obtained from three different transgenic mice. Cells stained with anti-EC-SOD antibodies are shown in brown. Intense staining in the synovium observed in the endotherial surface of synovium (arrow). Left panel, magnification, $\times 20$; right panel, magnification, $\times 40$. Scale bars: in Left, $100 \mu \mathrm{m}$; in right, $200 \mu \mathrm{m}$. 


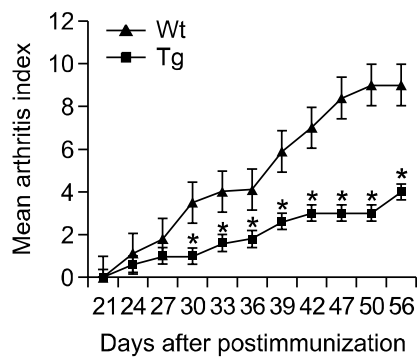

Figure 2. The overexprssion of EC-SOD in synovial tissue repressed inflammatory arthritis. After induction of arthritis in each mouse, disease development and severity were observed and determined as clinical score by blind manner of two trained inspectors. Disease severities were significantly reduced in transgenic mice on day 30 after primary immunization and this effect was maintained until all mice reach to terminal score $\left({ }^{*} P<0.05\right.$ vs arthritic wild type mice).
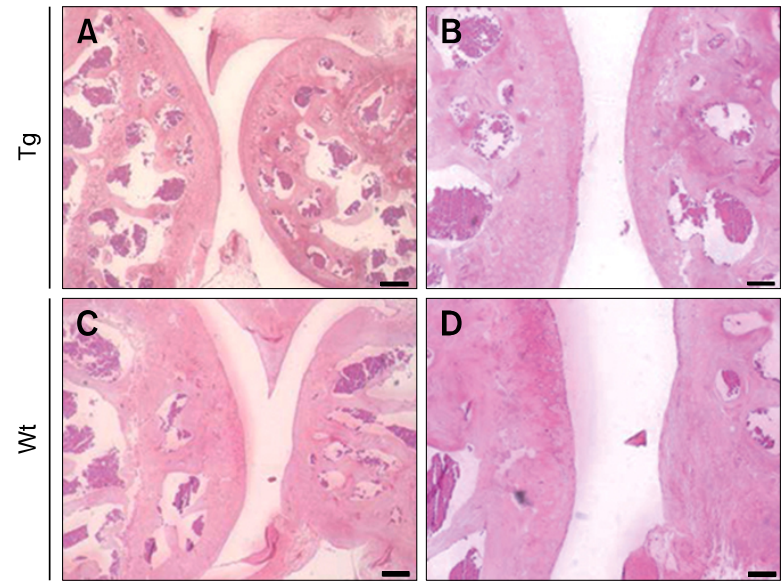

Figure 3. The over-expression of EC-SOD in the arthritic joint prevents destruction of cartilage and bone erosion. Histologic examination showed that the joints of wild type mice exhibit severe cartilage destruction and bone erosion. Mice were sacrificed on day 42 after the primary immunization. The left hind foot, which received collagen boosting, was excluded. The joint sections from transgenic mice (A, B) and wild type mice (C, D) are shown. The signs of tissue destruction were not seen in EC-SOD transgenic mice. Scale bars: in A, C, $100 \mu \mathrm{m}$; in B, D, $200 \mu \mathrm{m}$ ( $A, B$, magnification, $\times 20 ; C$ and $D$, magnification, respectively).

\section{Pathological role of the EC-SOD over-expression in arthritic mice}

To further analyze the pathologic role of the over-expression of EC-SOD in arthritic condition, the arthritis was induced by type II collagen immunization in transgenic mice. After arthritis induction, the clinical progressions were observed and scored until day 56. All mice showed detectable symptoms. However, transgenic mice showed delayed disease onset and the clinical scores were also significantly lower (Figure 2 ) as compared to the wild type mice $(P<0.05)$.
A

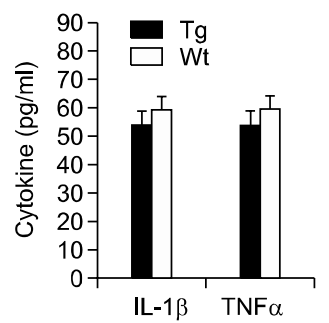

C

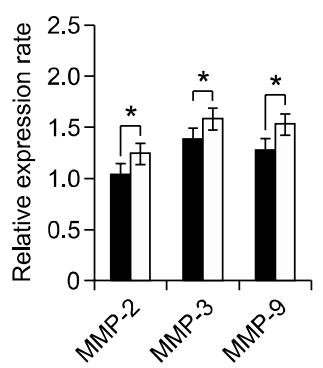

Figure 4. Cytokines and MMPs were decreased in FLS from EC-SOD transgenic mice during arthritis. The Levels of IL-1 $\beta$ and TNF $\alpha$ were determined in peripheral blood by ELISA (A). There is no significant difference between transgenic and wild type mice. For further examination, several cytokines (B) and MMPs (C) in FLS were tested by RT-PCR. Relative expression levels of each cytokines and MMPs were measured by the Image $\mathrm{J}$ software 1.38 . Whole cytokines and MMPs were repressed in FLS from EC-SOD transgenic mice but not IL-10 $\left({ }^{*} P<0.05\right.$ vs arthritic wild type mice).

\section{Histological analysis}

Histologic examination showed that the joints of wild type mice were heavily cartilage destruction and bone erosion (Figure 3, lower panel). In contrast, sections from transgenic mice showed no signs of tissue damage except for mild hyperplasia of the synovium (Figure 3, upper panel).

\section{The change of cytokines and MMPs in peripheral blood and arthritic FLS}

The levels of several cytokines and matrix metalloproteinases (MMPs) were also tested in transgenic mice. The concentrations of IL-1 $\beta$ and TNF $\alpha$ in peripheral blood were measured by ELISA. No significant difference between transgenic and wild type mice could be found (Figure 4A). Because EC-SOD was over-expressed in synovial tissue, various cytokines including IL-1 $\beta$, TNF $\alpha$ and MMPs in fibroblast-like synoviocyte from transgenic mice were also tested. FLS from inflamed paws re-stimulated by type II collagen and RT-PCR was performed. The expressions of IL- $1 \beta$ and TNF $\alpha$ were suppressed in the FLS of transgenic mice (Figure 4B). In addition, the expression levels of IL-2, IL-4 and IFN $\gamma$ were decreased in transgenic 
mice. Moreover the expression patterns of MMPs in arthritic FLS were also depressed in transgenic mice FLS (Figure 4C).

\section{Discussion}

In the present study, the induction of arthritis in transgenic mice, which over-express EC-SOD in synovial tissue, showed suppressed incidence and development of disease. These protective effects were not limited to the inhibition of key pro-inflammatory cytokines, such as IL-1 $\beta$ and TNF- $\alpha$, but included significant protection of the cartilage and bone.

The importance of maintaining a balance between oxidants and antioxidants in inflammatory diseases has been established by the amelioration of collagen-induced arthritis (CIA) by administration of EC-SOD through gene transfer or by treatment with an SOD mimetic (Salvemini et al., 2001). The EC-SOD deficient mice had shown much more severity in CIA (Ross et al., 2004). An imbalance in a disease state may be secondary to enhanced production of oxidants, to the decreased presence of antioxidants, or to a combination of these abnormal conditions. It is possible that decreased levels of EC-SOD in the joints of rheumatoid arthritis patients may contribute to more severe inflammation and tissue destruction (Slot et al., 1986). Although these studies suggested the importance of EC-SOD in inflammatory arthritis, there were no transgenic researches of EC-SOD in synovial tissue.

In a previous study, EC-SOD transgenic mouse reduced the incidence of tumor formation in the DMBA/TPA two-stage carcinogenesis model (Kim et al., 2005). Furthermore, engraftment of the EC-SOD transgenic mouse embryonic fibroblast repressed inflammatory cytokines and the Cll-specific T cells (Yu et al., 2008). In this study, the transgenic mice over-expressed EC-SOD in joint tissue and this protein was located in the lining layer of the synovium and endotherial cells in the sub lining. These results mean that EC-SOD transgenic mice could be a candidate for inflammatory arthritis. This hypothesis was tested in transgenic mice by CIA. During the disease progression, EC-SOD transgenic mice showed delayed disease incidence and the suppressed disease severity in $\mathrm{CIA}$. Interestingly, no difference could be found between IL-1 $\beta$ and TNF- $\alpha$ in peripheral blood from both transgenic and wild type mice. But these cytokines were down-regulated in fibroblast-like synoviocyte (FLS) in transgenic mice. In addition, other pro-inflammatory cytokines such as IL-2,
$\mathrm{IL}-4$, and IFN- $\gamma$ were also decreased in FLS. This means the difference in disease severity was accompanied by changes in cytokine production, particularly in the joints. FLS play critical roles in normal embryogenesis and mature joint functioning. In RA, however, FLS take on both a different character and set of roles. The FLS in RA (RAFLS) can be expended in cell culture over several passages and they escape from contact inhibition. These changes are often referred to as those of a tumor-like transformation since they result in aggressive and invasive behavior of RA-FLS in the adjacent cartilage and bone (Huber et al., 2006). Activation of FLS by a broad array of soluble factors and cell surface interactions overrides homeostatic function, promoting synthesis of molecules that help mediate joint destruction and inflammation (Mor et al., 2005). Inflammatory mediators that stimulate FLS include soluble, membraneassociated, and extracellular matrix-associated cytokines, chemokines, growth factors, and bioreactive lipids synthesized by both infiltlating leukocytes and FLS themselves. Several key cytokines that act on FLS such as TNF- $\alpha$ and IL-1 $\beta$ produced by macrophage (Bombara et al., 1993; Nakahara et al., 2003), IL-17 and IFN- $\gamma$ produced by T cells (Tasi et al., 1996; Kehlen et al., 2003; Hwang et al., 2004). Furthermore, in a recent study, the capacity of synovial cells to produce the superoxide anion was probed. A low level of constitutive superoxide production in RA cells was also observed in immortalized chondrocytes and endothelial cells (Moulton et al., 1997; Ago et al., 2004) and the superoxide anion in synovial cells was produced via an NADPH oxidase pathway (Chenevier-Gobeaux et al., 2006). These factors suggest the over-expression of EC-SOD in FLS would provide a better approach to treat RA.

The histological change and the expression of matrix metalloproteinases (MMPs) in FLS from arthritic mice were also analyzed. As shown in these results, tissue damages and bone erosion were not shown in EC-SOD transgenic mice and the levels of MMPs were also depressed in FLS. MMPs are $\mathrm{Zn}$-containing endopeptidases that are involved most prominently in tissue remodeling. Pro-inflammatory cytokines, growth factors and matrix molecules induce the expression of MMPs via transcriptional activation. In one model, patient derived RA-FLS co-implanted with human cartilage plugs under the renal capsule of SCID mice showed histologic evidence of FLS-mediated cartilage erosion. Additionally, this cartilage erosion was inhibited by transfection of constructs that blocked matrix-degrading enzymes such as MMP-1 or cathepsin L (Rutkauskaite et al., 2004; 
Schedel et al., 2004). Thus, histological protection in transgenic mice under in vivo arthritic condition would be due to the suppression of MMPs by EC-SOD over-expression in FLS.

In conclusion, these data suggest that the overexpression of EC-SOD in FLS contribute to the activation of FLS and protection from joint destruction by depressing the production of the pro-inflammatory cytokine and MMPs. These results provide EC-SOD transgenic mice would be a useful animal model for further inflammatory arthritis research.

\section{Methods}

\section{Animals}

DBA/1 mice, 6-8-week-old, were purchased from Charles River (Yokohama, Japan). The EC-SOD transgenic mice have been generated in a previous study (Kim et al., 2005). These mice were backcrossed with wild type DBA/1 mice through at least 6 generations.

\section{Over-expression of EC-SOD in the synovial tissue}

The total RNA was extracted from the joint tissue of transgenic mice with TRIzol reagents (M.R.C, CA), according to the manufacturer's protocol. The cDNA synthesis was performed using a reverse transcription system (Promega, $C A$ ). Synthesized cDNA was amplified with the following primers; EC-SOD, forward: 5'-CGG TTG AGA TAG ACA GG-3', reverse: 5'-TTA AGT GGT CTT GCA CTC G-3'. Immunohistochemical staining of synovium was performed on $5 \mu \mathrm{m}$ sections of formalin-fixed paraffin-embedded blocks. The sections were mounted on glass slides, deparaffinized in xylene, and rehydrated in a graded series of ethanol. The endogenous peroxidase activity was blocked by $3 \%$ hydrogen peroxide. After blocking the nonspecific binding by treating the slides with blocking solution (Santa Cruz, CA) at room temperature for $30 \mathrm{~min}$, the slides were incubated with goat anti-mouse SOD-3 anti-body (Santa Cruz, CA) at a $1 / 50$ dilution overnight at $4^{\circ} \mathrm{C}$. The sections were washed and incubated with the secondary anti-body, biotinylated goat anti-mouse IgG (Santa Cruz, CA). After washing and incubating, the sections were incubated with horseradish peroxidase conjugated streptavidin at room temperature for $30 \mathrm{~min}$. Diaminobenzidine was added to reveal the Ag. The sections were dehydrated, cleared, and mounted.

\section{Induction of arthritis and assessment}

Age-and sex-matched male DBA/1 and EC-SOD transgenic mice were immunized with bovine type II collagen (CII, Chondrex, WA) at 8-12 weeks of age, as described previously. Briefly, Cll was dissolved as $0.25 \%$ in 0.01 $\mathrm{N}$-acetic acids. Mice were immunized on day 0 with an intradermal injection of $100 \mu \mathrm{g} \mathrm{Cll}$, emulsified in a complete Freund's adjuvant (CFA). On day 14, the mice were boosted into the left footpad with the same amount of Cll in an incomplete Freund's adjuvant (IFA). Three weeks after primary immunization, the clinical scores of the mice were examined two to three times a week for the onset and severity of arthritis. The severity of arthritis was scored in a double-blind manner, with each paw exclude collagen injected paw, assigned a separate clinical score as follows: 0 = normal; $1=$ erythema and mild swelling confined to the ankle joint and toes; 2 = erythema and mild swelling extending from the ankle to the midfoot; 3 = erythema and severe swelling extending from the ankle to the metatarsal joints; and $4=$ ankylosing deformity with joint swelling (Myers et al., 1993; Jung et al., 2010).

\section{Histological assessment of the arthritic mice}

For a histological examination of the joints, the right hind limb was harvested from each mouse and fixed in $10 \%$ buffered formalin on day 42 . The limbs were decalcified in a histological decalcifying agent (Calci-Clear Rapid, National Diagnostics, GA), embedded in paraffin, sectioned, and stained with Hematoxylin and Eosin (H \& E). The fixed and stained slides of the joint sections were read by a trained observer.

\section{ELISA for IL-1 $\beta$ and TNF $\alpha$ in peripheral blood of arthritic mice}

Blood samples from arthritic mice were prepared by the eye-bleeding method on day 42 , post-immunization. The amount of IL- $1 \beta$ and TNF $\alpha$ in sera was measured by using commercially available ELISA kits (Quantikine Mouse IL-1 $\beta$ and TNF $\alpha$ immunoassay, R \& D Systems, MN). Optical absorbance was measured using an ELISA reader at 450 and $540 \mathrm{~nm}$.

\section{Cytokine and matrix metalloproteinases (MMPs) activities in synovial tissue of arthritic mice}

Fore and hind paws were removed at the ankle joint, the skin was removed from the inflamed paws, and the remaining tissue was carefully recovered with a scalpel in a volume of $1,000 \mu \mathrm{l} \mathrm{PBS}$. The synovial tissue was digested with $2.5 \%$ collagenase (Sigma) for $4 \mathrm{~h}$ at $37^{\circ} \mathrm{C}$ to obtain a single cell suspension. The fibroblast-like synoviocyte (FLS), from passages 3 through 7 were seeded in 24-well plates at $2 \times 10^{4}$ cells/well in DMEM supplemented $10 \%$ FBS and cultivated at $37^{\circ} \mathrm{C}$ for $24 \mathrm{~h}$. The cells were stimulated with type II collagen (Condrex) for $48 \mathrm{~h}$. For the analysis of cytokine and MMPs patterns, total RNA was extracted from FLS. Synthesized cDNA was amplified with PCR. The primer sequences for RT-PCR are like Supplemental Data Table S1. PCR products were screened in $1 \%$ agarose gel and relative expression levels of each cytokines were measured by the Image $\mathrm{J}$ software 1.38 .

\section{Statistical analysis}

Data are presented as mean $\pm \mathrm{SD}$. Comparisons of the numerical data between groups were performed by the paired or unpaired Mann-Whitney $U$ test. $P$-values $<0.05$ were considered statistically significant. 


\section{Supplemental data}

Supplemental data include a table and can be found with this article online at http://e-emm.or.kr/article/article_files/ SP-44-9-02.pdf.

\section{Acknowledgements}

This study was supported by a grant of the Korean Health Technology R\&D Project, Ministry of Health and Welfare, Republic of Korea (A090572) and a grant (PJ007849) from Woo Jang-Choon, RDA, Republic of Korea.

\section{References}

Ago T, Kitazono T, Ooboshi H, lyama T, Han YH, Takada J, Wakisaka M, Ibayashi S, Utsumi H, lida M. Nox4 as the major catalytic component of an endothelial $\mathrm{NAD}(\mathrm{P}) \mathrm{H}$ oxidase. Circulation 2004;109:227-33

Bombara MP, Webb DL, Conrad P, Marlor CW, Sarr T, Ranges GE, Aune TM, Greve JM, Blue ML. Cell contact between $T$ cells and synovial fibroblasts causes induction of adhesion molecules and cytokines. J Leukoc Biol 1993;54: 399-406

Burkhardt $\mathrm{H}$, Schwingel M, Menninger $\mathrm{H}$, Macartney HW, Tschesche $\mathrm{H}$. Oxygen radicals as effectors of cartilage destruction. Direct degradative effect on matrix components and indirect action via activation of latent collagenase from polymorphonuclear leukocytes. Arthritis Rheum 1986;29: 379-87

Carlsson LM, Jonsson J, Edlund T, Marklund SL. Mice lacking extracellular superoxide dismutase are more sensitive to hyperoxia. Proc Natl Acad Sci USA 1995;92: 6264-8

Chenevier-Gobeaux C, Lemarechal H, Bonnefont-Rousselot D, Poiraudeau S, Ekindjian OG, Borderie D. Superoxide production and NADPH oxidase expression in human rheumatoid synovial cells: regulation by interleukin- 1 beta and tumour necrosis factor-alpha. Inflamm Res 2006;55: 483-90

Fattman CL, Enghild JJ, Crapo JD, Schaefer LM, Valnickova Z, Oury TD. Purification and characterization of extracellular superoxide dismutase in mouse lung. Biochem Biophys Res Commun 2000;275:542-8

Feldmann M. Role of cytokines in rheumatoid arthritis. Annu Rev Immunol 1994;14:398-9

Goldring SR. Inflammatory mediatirs as essential elements in bone remodeling. Calcif Tissue Int 2004;73:97-100

Huber LC, Distler O, Tarner I, Gay RE, Gay S, Pap T. Synovial fibroblasts: key players in rheumatoid arthritis. Rheumatology (Oxford) 2006;45:669-75

Hwang SY, Kim JY, Kim KW, Park MK, Moon Y, Kim WU, Kim HY. IL-17 induces production of IL-6 and IL-8 in rheumatoid arthritis synovial fibroblasts via NF-kappaB- and PI3-kinase/ Akt-dependent pathways. Arthritis Res Ther 2004;6:R120-8

lyama S, Okamoto T, Sato T, Yamauchi N, Sato Y, Sasaki K, Takahashi M, Tanaka M, Adachi T, Kogawa K, Kato J,
Sakamaki S, Niitsu Y. Treatment of murine collagen-induced arthritis by ex vivo extracellular superoxide dismutase gene transfer. Arthritis Rheum 2001;44:2160-7

Kehlen A, Pachnio A, Thiele K, Langner J. Gene expression induced by interleukin-17 in fibroblast-like synoviocytes of patients with rheumatoid arthritis: upregulation of hyaluronan-binding protein TSG-6. Arthritis Res Ther 2003;5:R18692

Kim SH, Kim MO, Gao P, Youm CA, Park HR, Lee TS, Kim KS, Suh JG, Lee HT, Park BJ, Ryoo ZY, Lee TH. Overexpression of extracellular superoxide dismutase (EC-SOD) in mouse skin plays a protective role in DMBA/TPA-induced tumor formation. Oncol Res 2005;15:333-41

Koga S, Ogawa S, Kuwabara K, Brett J, Leavy JA, Ryan J, Koga Y, Plocinski J, Benjamin W, Burns DK, et al. Synthesis and release of interleukin 1 by reoxygenated human mononuclear phagocytes. J Clin Invest 1992;90:1007-15

Marklund SL. Extracellular superoxide dismutase. Methods Enzymol 2002;349:74-80

McCord JM. Free radicals and inflammation: protection of synovial fluid by superoxide dismutase. Science 1974;185: 529-31

Mor A, Abramson SB, Pillinger $\mathrm{MH}$. The fibroblast-like synovial cell in rheumatoid arthritis: a key player in inflammation and joint destruction. Clin Immunol 2005;115:118-28

Moulton PJ, Hiran TS, Goldring MB, Hancock JT. Detection of protein and mRNA of various components of the NADPH oxidase complex in an immortalized human chondrocyte line. Br J Rheumatol 1997;36:522-9

Myers LK. Collagen-induced arthritis. In Current protocols in immunology (Coligan, Kruisbeek AM, Margulies DH, Shevach EM, Strober W, eds), 1993, 11-4, John Wiley and Sons, Inc., NJ

Nakahara H, Song J, Sugimoto M, Hagihara K, Kishimoto T, Yoshizaki K, Nishimoto N. Anti-interleukin-6 receptor antibody therapy reduces vascular endothelial growth factor production in rheumatoid arthritis. Arthritis Rheum 2003;48: 1521-9

Ookawara T, Imazeki N, Matsubara O, Kizaki T, Oh-Ishi S, Nakao C, Sato Y, Ohno H. Tissue distribution of immunoreactive mouse extracellular superoxide dismutase. Am J Physiol 1998;275:C840-7

Ross AD, Banda NK, Muggli M, Arend WP. Enhancement of collagen-induced arthritis in mice genetically deficient in extracellular superoxide dismutase. Arthritis Rheum 2004; 50:3702-11

Rutkauskaite E, Zacharias W, Schedel J, Muller-Ladner U, Mawrin C, Seemayer CA, Alexander D, Gay RE, Aicher WK, Michel BA, Gay S, Pap T. Ribozymes that inhibit the production of matrix metalloproteinase 1 reduce the invasiveness of rheumatoid arthritis synovial fibroblasts. Arthritis Rheum 2004;50:1448-56

Salvemini D, Mazzon E, Dugo L, Serraino I, De Sarro A, Caputi AP, Cuzzocrea S. Amelioration of joint disease in a rat model of collagen-induced arthritis by M40403, a superoxide dismutase mimetic. Arthritis Rheum 2001;44:2909-21 
Schedel J, Seemayer CA, Pap T, Neidhart M, Kuchen S, Michel BA, Gay RE, Muller-Ladner U, Gay S, Zacharias W. Targeting cathepsin $L(C L)$ by specific ribozymes decreases $C L$ protein synthesis and cartilage destruction in rheumatoid arthritis. Gene Ther 2004;11:1040-7.

Simeonova PP, Luster MI. Iron and reactive oxygen species in the asbestos-induced tumor necrosis factor-alpha response from alveolar macrophages. Am J Respir Cell Mol Biol 1995;12:676-83

Slot JW, Geuze HJ, Freeman BA, Crapo JD. Intracellular localization of the copper-zinc and manganese superoxide dismutases in rat liver parenchymal cells. Lab Invest 1986; 55:363-71

Sweeney SE, Firestein GS. Rheumatoid arthritis: regulation of synovial inflammation. Int J Biochem Cell Biol 2004;36: $372-8$

Tiku ML, Shah R, Allison GT. Evidence linking chondrocyte lipid peroxidation to cartilage matrix protein degradation. Possible role in cartilage aging and the pathogenesis of osteoarthritis. J Biol Chem 2000;275:20069-76

Tsai C, Diaz LA Jr, Singer NG, Li LL, Kirsch AH, Mitra R, Nickoloff BJ, Crofford LJ, Fox DA. Responsiveness of human $T$ lymphocytes to bacterial superantigens presented by cultured rheumatoid arthritis synoviocytes. Arthritis Rheum 1996;39:125-36

Tsan MF. Superoxide dismutase and pulmonary oxygen toxicity. Proc Soc Exp Biol Med 1997;214:107-13

Volk T, Gerst J, Faust-Belbe G, Stroehmann A, Kox WJ. Monocyte stimulation by reactive oxygen species: role of superoxide and intracellular $\mathrm{Ca}^{2+}$. Inflamm Res 1999;48: 544-9

Yu DH, Kim MO, Kim SH, Shin MJ, Kim BS, Kim HJ, Lee SR, Lee SG, Yoo SA, Kim WU, Hyun BH, Park YS, Kim TY, Ryoo $Z Y$. The therapeutic effect of extracellular superoxide dismutase (EC-SOD) mouse embryonic fibroblast (MEF) on collagen-induced arthritis (CIA) mice. Cell Transplant 2008;17: 1371-80 